\title{
High Throughput Kinetic Assay for Screening Potential Inhibitors of Sickle Hemoglobin Polymerization
}

Ahmed S Mehanna*

Department of Pharmaceutical Sciences, School of Pharmacy, MCPHS University, Boston, MA, USA

\begin{abstract}
The current manuscript describes a high throughput assay designed to identify organic compounds with potential inhibitory effects on sickle hemoglobin polymerization. The assay is fast, economic and reproducible. In just 20-minutes, a test compound can be screened for anti-polymerization activity at five different concentrations; each in quadruple; using as little as $10 \mathrm{mg}$ of purified sickle hemoglobin. The assay was conducted in high phosphate buffer concentration $(1.5 \mathrm{M})$, a concentration that allows sickle hemoglobin to polymerize at a very low concentration of $50.0 \mu \mathrm{M}$. The new assay was validated by evaluating the inhibitory effects of the amino acid phenylalanine, a standard control used in all gelation assays, and hydroxyl urea, the only FDA approved drug to treat sickle cell anemia. Phenylalanine showed a reproducible and concentration-dependent delay of sickle hemoglobin polymerization at a concentration range of $25-75 \mathrm{mM}$. Hydroxyurea; although its action is thought to be through promoting fetal hemoglobin formation, was found to have direct inhibitory effects on sickle hemoglobin polymerization but at a high concentration range of $64-500 \mathrm{mM}$. The assay was applied for random screening of several organic compounds and 2-thio-salicylic acid was identified to be a powerful inhibitor for polymerization at much lower concentration range of 0.1-1.6 mM.
\end{abstract}

Keywords: Sickle cell anemia; Sickle hemoglobin polymerization; High throughput screening assay; Drug discovery; 2-Mercaptobenzoic acid

\section{Introduction}

Sickle cell anemia is a genetic disease resulting from a single point mutation that results in the replacement of the hydrophilic glutamic amino acid at the $6^{\text {th }}$ position of the hemoglobin $\beta$-chain with the more lipophilic amino acid valine. The mutant hemoglobin, frequently referred to as Hobs, polymerizes inside the red blood cells at low oxygen tension leading to cell distortion into the sickle shape, hence the term sickle cell anemia, that in turn, leads to vascular occlusion and the serious deadly complications.

Although all aspects of the disease have been extensively investigated and reviewed [1-3]; a definite treatment for the disease still not at hand. A new gene therapy approach has been recently reported as potential alternative to drug therapy [4].

Attempts to discover new anti-sickling agents have always been hampered by the unavailability of quick screening method to assess potential in vitro anti-polymerization activity. In 1976, Hofrichter et al. developed the most widely used protocol to quantitatively evaluate anti-gelling effects of potential inhibitors [5]. In spite of the history and value of the assay in the identification of anti-sickling activities of several organic compounds, however, the assay requires availability of huge amounts of sickle cell blood to purify and obtain and a very high concentration of sickle hemoglobin of $3.0 \mathrm{mM}$ to induce the polymerization. For the application of Hofichter's assay, see several of our previous related publications [6-13]. To offset that need of large amount of sickle hemoglobin, we developed special cells to reduce the needed amounts of hemoglobin to run the assay [14]. Even with success of that modification [15], the modified assay still requires the availability of whole sickle blood as a source of Hobs. With the recent advancement in technology and the widespread use of high throughput technology, several new high throughput assay methods have been recently reported in the literature to screen compounds for anti-polymerization activities [16-18], unfortunately, both use whole blood samples.

\section{Current Assay}

The absence of rapid high throughput screening assay for anti- polymerization activities together with the shortcomings of the recently reported assays, prompted us develop the current assay. The assay is fast and economic screening technique that does not use whole sickle blood, rather commercially available purified sickle hemoglobin provided by Sigma-Aldrich. Hobs polymerization was achieved at a very low concentration of $50.0 \mu \mathrm{M}$ by conducting the assay in high phosphate buffer $(1.5 \mathrm{M})$ medium [19]. Using as little as $250 \mu \mathrm{l}$ of 40 $\mathrm{mg} / \mathrm{ml} \mathrm{HBS}$ solution; a given test compound can be evaluated at 5 different concentrations; each in quadruple, in a period of 20 minutes. HbS-polymerization was monitored using plate reader technology and through recording the optical density at $700 \mathrm{~nm}$ wave length [20]; every 30 seconds for each well over 20 -minutes period. The data points are saved as excel file, and the polymerization curve is generated using Sigma Plot program. The current assay monitors HBS polymerization under deoxygenated condition with time for each compound concentration. It must be indicated that monitoring the delay in the polymerization process is a very valuable approach to decrease the precipitation of potential sickle cell crisis in vivo. All what is needed is few seconds of delay in the cellular polymerization to allow the red blood cells to go through the vascular venous bed, where the oxygen tension is low, to become re-oxygenated again in the arteries where it does not polymerize [21].

Two compounds were selected to validate the assay: the amino acid phenyl alanine and the drug hydroxyurea. The choice of phenylalanine for evaluation is based on its frequent use as a positive control in the traditional anti-polymerization assay developed by Hofrichter et al.

*Corresponding author: Ahmed S Mehanna, Department of Pharmaceutical Sciences, School of Pharmacy, MCPHS University, 179 Longwood Avenue, Boston, MA 02115, USA, Tel: 6177322955; E-mail: ahmed.mehanna@mcphs.edu

Received June 29, 2017; Accepted July 06, 2017; Published July 10, 2017

Citation: Mehanna AS (2017) High Throughput Kinetic Assay for Screening Potential Inhibitors of Sickle Hemoglobin Polymerization. Med Chem (Los Angeles) 7: 193-196. doi: 10.4172/2161-0444.1000455

Copyright: (ㅇ 2017 Mehanna AS. This is an open-access article distributed under the terms of the Creative Commons Attribution License, which permits unrestricted use, distribution, and reproduction in any medium, provided the original author and source are credited. 
and hydroxyurea was chosen for evaluation because it is the only FDA approved drug for treating sickle cell anemia. After confirming the assay validity, several organic compounds were screened for activity; and 2-mercapto benzoic acid (thiosalicylic acid) was identified to be a very potent inhibitor for Hobs polymerization in a concentrationdependent manner. Figure 1 depicts the chemical structures for the evaluated compounds.

\section{Experimental}

\section{Material and methods}

Potassium dihydrogen Phosphate, Potassium meta-bisulfite, Phenylalanine, 2-mercapto-salicylic acid, hydroxyurea: Sigma Aldrich, Purified Sickle hemoglobin powder provided by Sigma - Aldrich provided as $50 \%$ product stabilized with $50 \%$ buffer, Synergy Plate reader, 96-Half well plates.

\section{Kinetic gelation assay}

A solution of $200.0 \mu \mathrm{M}$ sickle hemoglobin was prepared by dissolving $10 \mathrm{mg}$ of powdered Hobs supplied by Sigma-Aldrich (containing $50 \%$ stabilizing buffer), in $250 \mu \mathrm{L}$ of $1.5 \mathrm{M}$, pH 7.4 potassium phosphate buffer. Each of the half-well plate cells was charged with 10 $\mu \mathrm{L}$ of this Hobs solution. To each well, $20 \mu \mathrm{L}$ of the test compound (prepared in $1.5 \mathrm{M}$ phosphate buffer), plain buffer as control, were added. The polymerization process was triggered by adding $10 \mu \mathrm{L}$ of $1.0 \mathrm{M}$ potassium meta-bisulfite solution to each well and the plate was introduced into the plate reader, preheated to $37^{\circ} \mathrm{C}$, and programmed to record the optical density at $700 \mathrm{~nm}$, for each well every 30 second over a total period of 20 -minute (total of 40 recorded points for each well). The generated excel file was then loaded into Sigma plot program to generate the kinetic plots showing the delay in polymerization as a function of time in seconds (Figures 2-4). A total number of the<smiles>N[C@@H](Cc1ccccc1)C(=O)O</smiles>

Phenyl Alanine

acid<smiles>NC(=O)NO</smiles>

Hydroxyurea<smiles>O=C(O)c1ccccc1S</smiles>

2-Mercaptobenzoic

Figure 1: Chemical structures for tested compounds.

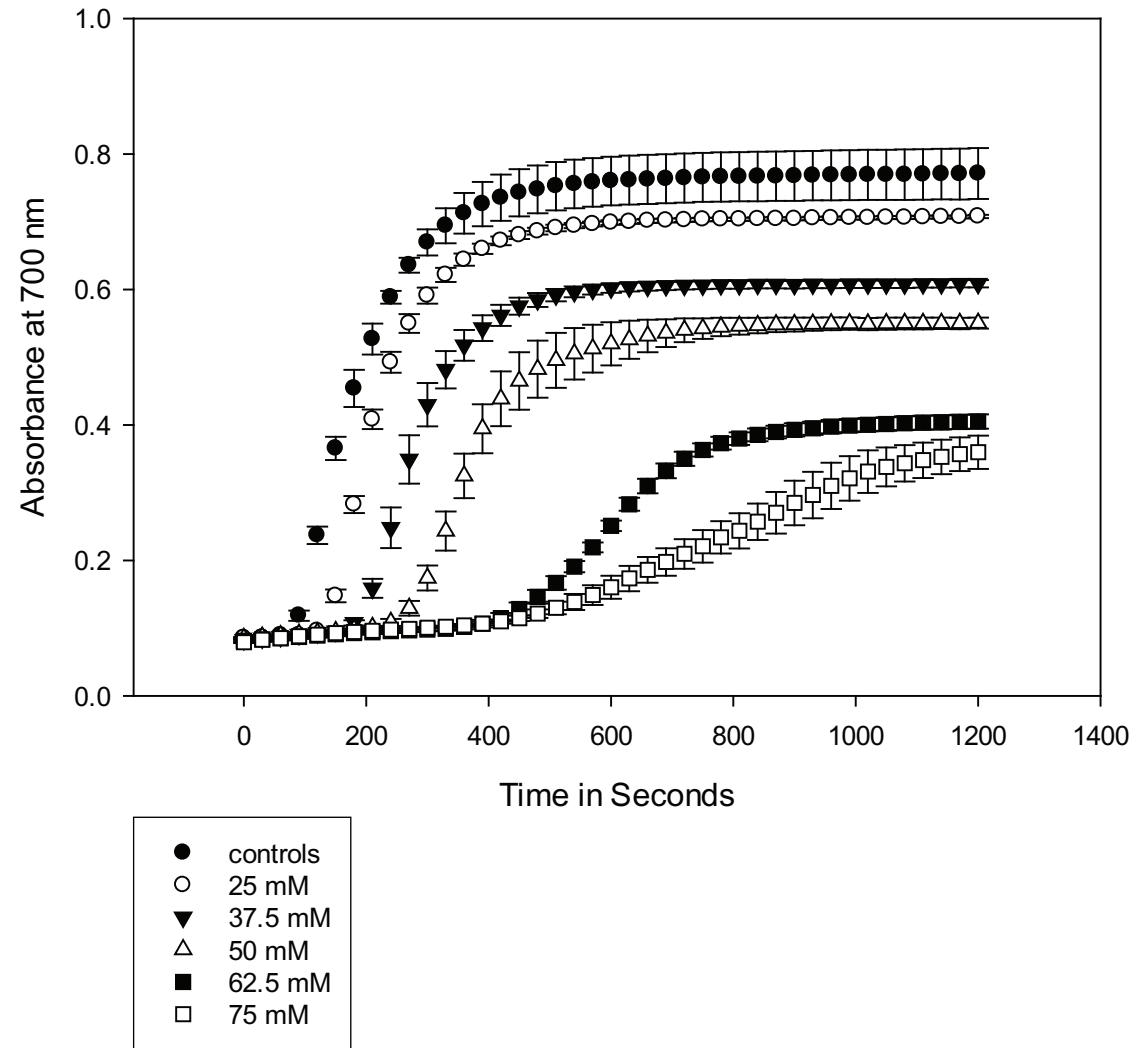

*All data points are average of 5 different runs, in quadruple application for each concentration.

Figure 2: Inhibitory effects of phenylalanine on HBS polymerization*. 


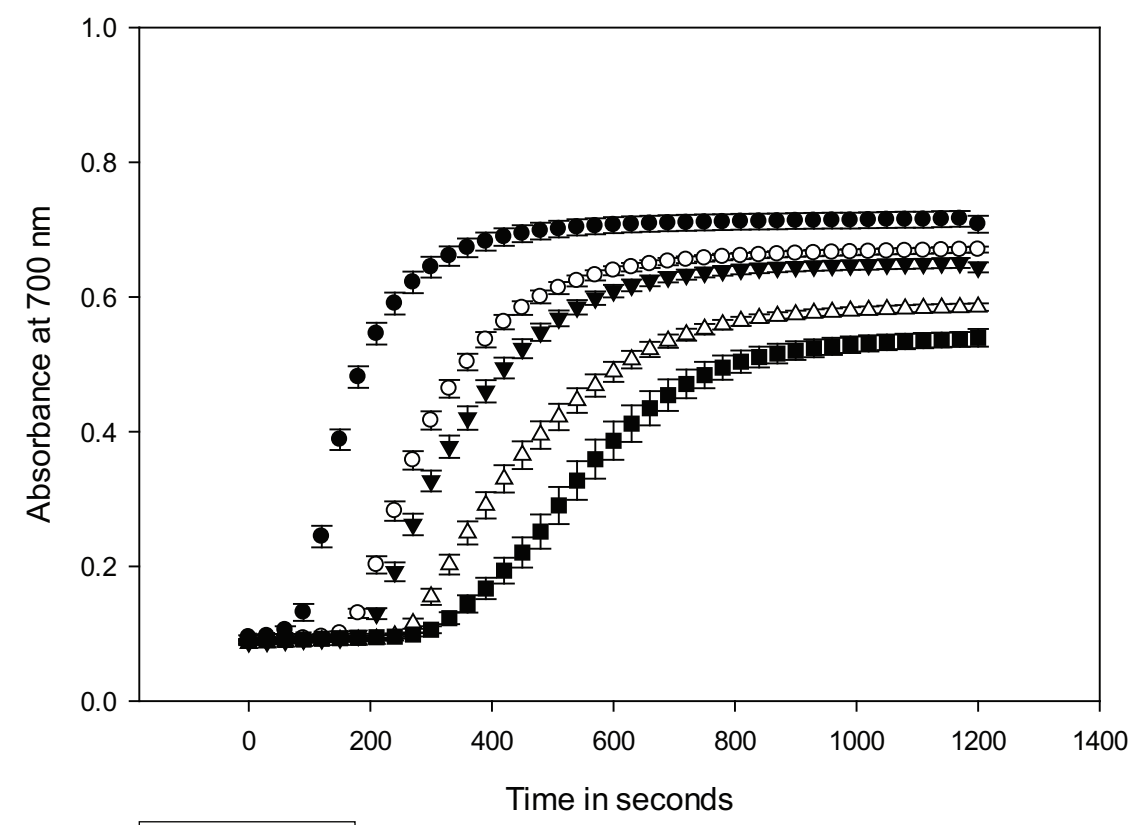

\begin{tabular}{|ll|}
\hline - & Controls \\
$\circ$ & $64.0 \mathrm{mM}$ \\
$\nabla$ & $125 \mathrm{mM}$ \\
$\Delta$ & $250 \mathrm{mM}$ \\
- & $500 \mathrm{mM}$ \\
\hline
\end{tabular}

"All data points are average of 5 different runs, in quadruple application for each concentration.

Figure 3: Inhibitory effects of hydroxyurea on HBS polymerization*.

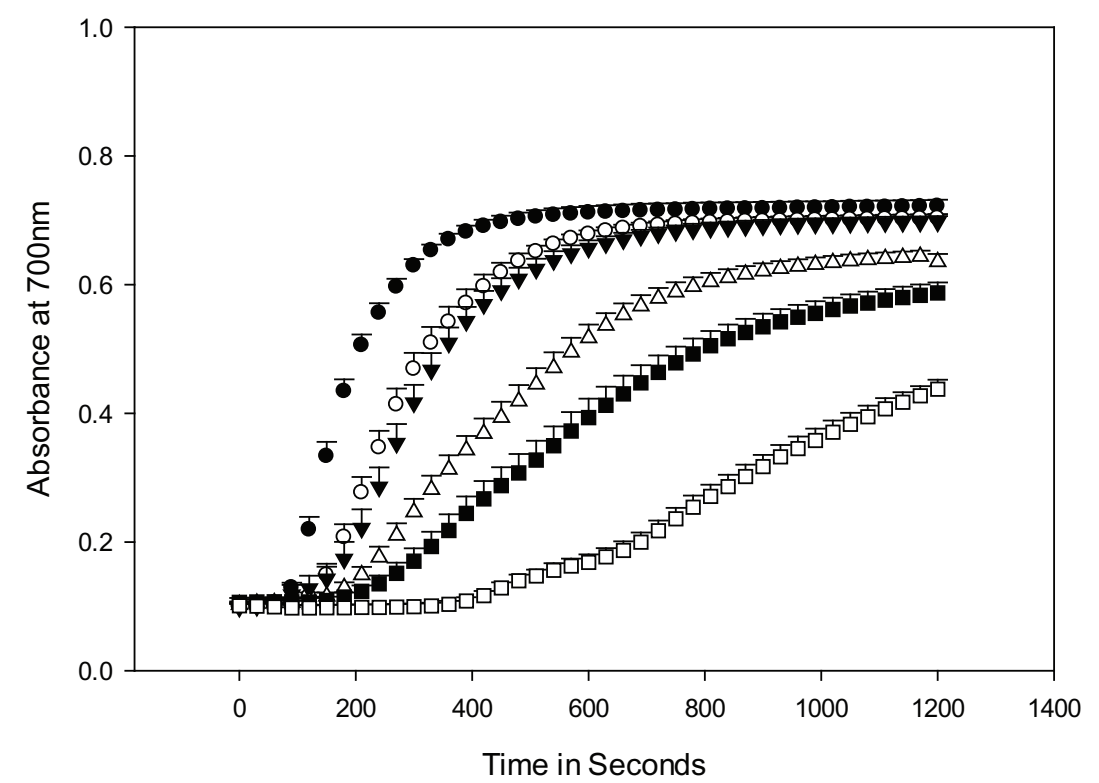

$$
\begin{array}{ll}
\bullet & \text { controls } \\
\circ & 0.1 \mathrm{mM} \\
\nabla & 0.2 \mathrm{mM} \\
\Delta & 0.4 \mathrm{mM} \\
\square & 0.8 \mathrm{mM} \\
\square & 1.6 \mathrm{mM}
\end{array}
$$

*All data points are average of 5 different runs, in quadruple application for each concentration

Figure 4: Inhibitory effects of 2-mercaptobenzoic acid on HBS polymerization*. 
plate wells employed were 24: one as blank, three as controls (Hobs, buffer, and sodium meta-bisulfite), and twenty wells for 5 different concentrations of the test compound; each in quadruple. The total assay volume in each well is $40 \mu \mathrm{L}$. The final Hobs concentration after mixing with all reagents is now $10 \mathrm{mg} / \mathrm{ml}(50.0 \mu \mathrm{M})$.

\section{Results and Discussion}

\section{Phenylalanine}

Figure 2 depicts the effect of phenylalanine concentration on the kinetics of Hobs polymerization. The amino acid was found to delay the polymerization and shift the polymerization curve to the right, in a concentration-dependent fashion, over a concentration range of 25$75 \mathrm{mM}$.

\section{Hydroxyurea}

On the other hand, hydroxyurea was evaluated for direct inhibitory effects on the polymerization process under the current assay conditions. As stated earlier; hydroxyurea was chosen for evaluation because it is currently the only FDA approved drug for treating sickle cell anemia. The widely accepted mechanism of its action is through promoting the biosynthesis of fetal hemoglobin ( $\mathrm{HbF}$ ), a hemoglobin species that, unlike HSB, does not polymerize at low oxygen tension. We were interested to assess whether that is the only beneficial effect of the drug, or it may have direct inhibitory effect on the polymerization process as well. Figure 3, depicts that hydroxyurea has direct inhibitory effects on the polymerization process, though at very high concentration range of 64-500mM. The latter, confirms that the in vivo mechanism of action of the drug cannot be through direct inhibition of the polymerization process. However, testing of hydroxyurea in our assay in addition to excluding the direct inhibitory effects on Hobs polymerization, as a possible second mechanism, provides evidence that the assay can assess the anti-polymerization activity in a concentration dependent manner.

\section{2-Mercapto benzoic acid (Thiosalicylic acid)}

The reproducibility in collecting data screening data for phenyl alanine and hydroxyurea prompted us to randomly screen few compounds that existed in the lab. To our surprise and delight; thiosalicylic acid was found to have inhibitory activities at much lower concentration range compared to that of phenylalanine and hydroxyurea. As depicted in Figure 4, thiosalicylic acid inhibits Hobs polymerization in a concentration range of 0.1-1.6 mM. It is must be indicated that thiosalicylic acid has been previously approved in the past for use as analgesic and anti-inflammatory drug. The latter pharmacological effects are required for patients with sickle cell disease who always suffer from painful crises.

\section{Conclusion}

A new high throughput kinetic assay has been developed to screen organic compound for potential anti-sickling activity. The assay has been proven to be accurate, reproducible and economic regarding the amount of sickle hemoglobin needed to screen compounds. The new assay allows screening of the test compound at 5 different concentrations, each in quadruple in a total time of 20 minutes. Screening of several organic compounds with the current assay revealed that 2-mercaptobenzoic acid is a potent inhibitor for $\mathrm{HbS}$ polymerization at a concentration range of 0.1-1.6 mM.

\section{Acknowledgements}

The author would like to thank MCPHS University for funding and supporting this research.

\section{References}

1. Mehanna AS (2001) Sickle Anemia and Anti-sickling Agents Then and Now. Current Medicinal Chemistry 8: 79-88.

2. Hankins J, Aygun B (2009) Pharmacotherapy in sickle cell disease--state of the art and future prospects. Br J Hematol 3: 296-308.

3. Vasaikar NB, Sonawane S, Patil S, Borse LB (2015) A review on sickle cell anemia. Pharma Science Monitor 2: 118-132.

4. Ribeil JA, Hacein BAS, Payen E, Magnari A (2017) Brief Report: Gene Therapy in a Patient with Sickle Cell Disease. N Engl J Med 367: 848-855.

5. Hofrichter J, Ross PD, Eaton WA (1976) Supersaturation in Sickle Cell Hemoglobin Solutions. Proc Natl Acad Sci USA 9: 3035-3039.

6. Abraham DJ, Mehanna AS, Williams FL (1982) Design, synthesis, and testing of potential antisickling agents. 1. Halogenated benzyloxy and phenoxy acids. J Med Chem 9: 1015-1017.

7. Abraham DJ, Gazze DM, Kennedy PE, Mokotoff M (1984) Design, synthesis, and testing of potential antisickling agents. 5. Disubstituted benzoic acids designed for the donor site and proline salicylates designed for the acceptor site. J Med Chem 2: 1549-1559.

8. Abraham DJ, Mehanna AS, Williams FL, Cragoe EJ (1989) Design, synthesis and testing of potential antisickling agents. 7. Ethacrynic acid analogs. J Med Chem 11: 2460-24677.

9. Randad R, Mahran MA, Mehanna AS, Abraham DJ (1991) Allosteric Modifiers of Hemoglobin. J Med Chem 34: 752-757.

10. Mehanna AS, Abraham DJ (1990) Comparison of crystal and solution hemoglobin binding of selected antigelling agents and allosteric modifiers. Biochemistry 16: 3944-3952.

11. Patwa DC, Abraham DJ, Hung TC (1987) Design, synthesis, and testing of potential antisickling agents. 6 . Rheologic studies with active phenoxy and benzyloxy acids. Blood Cells 3: 589-598.

12. Sheh L, Mokotoff M, Abraham DJ (1987) Design, synthesis, and testing of potential antisickling agents. 9. Cyclic tetrapeptide homologs as mimics of the mutation site of hemoglobin S. International Journal of Peptide and Protein Research 4: 509-520.

13. Fatope MO, Abraham DJ (1987) Design, synthesis, and testing of potential antisickling agents. 10. 2,2-Dimethylchroman-6-ylalkanoic acids. J Med Chem 11: 1973-1977.

14. Richard AJ, Mehenna AS, Abraham DJ (1991) Cell Design for Reducing the Amount of Sickle Cell Hemoglobin Needed Per Gelation Assay. Hemoglobin 2: $125-128$.

15. Abraham DJ, Mehanna AS, Wireko FC, Thomas RP (1991) Vanillin, a potential agent for the treatment of sickle cell anemia. Blood 6: 1334-1341.

16. Pais E, Cambridge JS, Johnson CS, Meiselman HJ, Fisher TC, et al. (2009) A novel high-throughput screening assay for sickle cell disease drug discovery. Biomol Screen 3: 330-336.

17. Li Q, Henry ER, Hofrichter JS, Jeffrey F, Dunkelberger EB, et al. (2017) Kinetic assay shows that increasing red cell volume could be a treatment for sickle cell disease. Proceedings of the National Academy of Sciences USA 5: E689-E696.

18. Nakagawa A, Francis EL, Wassaf D, Freedman Y, Casalena D, et al. (2014) Identification of a small molecule that increases hemoglobin oxygen affinity and reduces SS erythrocyte sickling. ACS Chemical Biology 10: 2318-2325.

19. Louderback JG, Ballas SK, Kim-Shapiro DB (1999) Sickle Hemoglobin Polymer Melting in High Concentration Phosphate Buffer. Biophysical Journal 4: 22162222.

20. Molfat K, Gibson QH (1974) The rates of polymerization and depolymerization of sickle cell hemoglobin. Biochem Biophys Res Commun 61: 237.

21. Mozzarelli A, Hofrichter J, Eaton WA (1987) Delay time of hemoglobin S polymerization prevents most cells from sickling in vivo. Science 237: 500-506. 